\title{
Indicadores do bem-estar em suínos
}

\author{
Welfare indicators in swine
}

\section{Raíssa Ivna Alquete de Arreguy Baptista ${ }^{\mathrm{I}}$ Giovani Rota Bertani ${ }^{\mathrm{II}}$ Clara Nilce Barbosa ${ }^{\mathrm{I}}$}

\section{- REVISÃO BIBLIOGRÁFICA -}

RESUMO

A busca por produtos de qualidade exige do produtor mudanças no sistema de produção de suíno que priorizem, em particular, o bem-estar do animal. As mudanças são necessárias para atender à demanda da sociedade e ampliar os mercados internos e externos. O bem-estar na espécie suína pode ser avaliado por meio das respostas comportamentais, fisiológicas, ligadas à sanidade e à produção. Em função do exposto, o objetivo deste trabalho é revisar a literatura em relação aos critérios científicos utilizados para indicar o bem-estar da espécie suína nos sistemas de produção.

Palavras-chave: comportamento, estresse, fisiologia, suíno.

\section{ABSTRACT}

In order to obtain good quality products, the swine production system should prioritize the animals welfare. Changes are necessary to meet society's demand and expand domestic and foreign markets. The swine's welfare can be assessed by behavioral and physiological traits related to health and production. Thus, our goal is to review in the literature what are the scientific criteria that are used to indicate the swine welfare in the production systems.

Key words: behavior, physiology, stress, swine.

\section{INTRODUÇÃO}

A industrialização da agricultura no período pós-segunda guerra mundial provocou mudanças radicais nos métodos de criação. Essas mudanças eram caracterizadas principalmente por números mais altos de animais mantidos juntos em espaços marcadamente reduzidos (GONYOU, 1994; BROOM \& FRASER, 2010). Os estudos de cientistas e filósofos sobre o bem-estar Animal (BEA) começaram a ser desenvolvidos na década 70 com o objetivo de entender e articular o bom relacionamento entre os animais e o homem. Esses estudos foram impulsionados pelo interesse público em saber como os animais eram criados e tratados (FRASER, 2000). Posteriormente, diversos trabalhos nessa área geraram conceitos sobre o BEA (BROOM \& MOLENTO, 2004), relacionados à capacidade do animal em se ajustar ao ambiente (BROOM, 1991), ao estado em que os animais se encontram (GALHARDO \& OLIVEIRA, 2006) e à qualidade de vida deles (FRAJBLAT et al., 2008).

Apesar de existirem muitos conceitos sobre BEA, atualmente, a definição proposta pelo comitê Brambell é a mais utilizada. Esse conceito foi elaborado na Inglaterra pelo professor John Webster e adotado pelo Farm Animal Welfare Council (FAWC). Ele se fundamenta nas cinco liberdades inerentes aos animais:

'Departamento de Medicina Veterinária, Universidade Federal Rural de Pernambuco (UFRP), Av. Dom Manoel de Medeiros, S/N, Dois Irmãos, 52171-900, Recife, PE, Brasil. E-mail: raissaivna @yahoo.com.br. *Autor para correspondência

"Departamento de Bioquímica, Laboratório de Imunopatologia Keizo Asami (LIKA), Universidade Federal de Pernambuco (UFPE), Recife, PE, Brasil. 
a liberdade fisiológica (ausência de fome e de sede); a liberdade ambiental (edificações adaptadas); a liberdade sanitária (ausência de doenças e de fraturas); a liberdade comportamental (possibilidade de exprimir comportamentos normais) e; a liberdade psicológica (ausência de medo e de ansiedade) (SILVA \& MIRANDA, 2009; GRANDIN \& JOHNSON, 2010).

A suinocultura pode ser considerada uma das formas mais intensivas de criação. No Brasil, predomina o sistema de confinamento intensivo com objetivo de otimizar o desempenho econômico e produtivo. Por outro lado, os produtores sofrem a pressão da sociedade para que se valorize o BEA, sendo necessários mais conhecimentos científicos na área. A União Européia (UE) destaca-se na adoção de medidas relacionadas ao BEA, tendo aprovado leis rigorosas em diversas áreas (MOLENTO, 2005), em especial, no sistema de produção de suínos. No Brasil, a questão do BEA vem ganhando espaço pelo interesse dos produtores em ampliar os mercados mais exigentes, tais como, China, Estados Unidos e a UE.

$\mathrm{O}$ perfil do produtor brasileiro, ainda que discretamente, vem sofrendo algumas mudanças. A busca da sociedade e do mercado externo por produtos éticos e de qualidade tem conquistado alguns progressos na produção de animais, o que torna necessário estabelecer critérios que avaliem o bem-estar dos suínos em seus sistemas de criação. O objetivo deste trabalho foi revisar a literatura em relação aos critérios científicos utilizados para indicar o bem-estar da espécie suína nos sistemas de criação.

\section{Avaliação do bem-estar animal}

Na produção animal, a avaliação do BEA é complexa, pois envolve aspectos relacionados às instalações, ao manejo e ao ambiente. De acordo com ZANELLA (1995) e CANDIANI et al. (2008), o BEA pode ser avaliado através de aspectos comportamentais, fisiológicos, sanitários e produtivos.

BROOM \& MOLENTO (2004) descreveram que alguns indicadores de BEA podem ser mensurados por meio de avaliações fisiológicas, tais como: a frequência cardíaca, a atividade adrenal e a resposta do sistema imunológico. As mensurações comportamentais têm a mesma importância na avaliação do bem-estar. Os comportamentos anormais, tais como as estereotipias, a automutilação, o canibalismo, a agressividade excessiva e a apatia em suínos indicam condições desfavoráveis ao seu bem-estar (ZANELLA, 1995; BROOM \& MOLENTO, 2004).

\section{Critérios comportamentais \\ O comportamento é uma das características mais importantes, pois é fundamental nas adaptações}

das funções biológicas e representa a parte do organismo que interage com o ambiente (SNOWDON, 1999). A observação das alterações comportamentais é considerada um dos métodos mais rápidos e práticos quando se avalia o BEA (POLETTO, 2010). Por meio da observação comportamental, é possível mensurar o estado do indivíduo em relação ao seu ambiente (BROOM, 1991).

Os comportamentos destrutivos são aqueles que causam lesões nos animais, tais como: as mordeduras e os vícios de sucção da cauda, orelha, flanco e vulva, bem como os comportamentos agressivos (ZANELLA, 1995; SOBESTIANSKY \& ZANELLA, 2007; POLETTO, 2010). As interações agonísticas são um meio de definição da hierarquia social em baia coletiva após a mistura de grupos (ANDERSEN et al., 2000). Esses comportamentos podem estar relacionados com uma série de fatores estressantes, causados por problemas nas instalações e no manejo inadequado dos animais (SOBESTIANSKY \&ZANELLA, 2007).

De acordo com JENSEN (2009), as estereotipias são uma forma particular de comportamento anormal. Elas podem ser descritas como movimentos repetitivos que ocorrem várias vezes e ocupam quantidade substancial do tempo do animal. Quando os suínos são confinados em baias ou presos por amarras por longo tempo, alguns indivíduos evidenciam comportamentos estereotipados, enquanto outros se tornam extremamente inativos e nãoresponsivos (BROOM, 1991). Nos suínos, as estereotipias mais comuns são: enrolar a língua, falsa mastigação e mastigação de parte das instalações (barras, portas, entre outros) (ZANELLA, 1995; POLETTO, 2010).

O comportamento apático, evidenciado pela inatividade excessiva, ocorre quando o ambiente não é estimulante. Esse tipo comportamental indica que o indivíduo em questão está com dificuldade em lidar com o ambiente (BROOM, 1991). KIEFER et al. (2009) verificaram que o estresse térmico $\left(31,3^{\circ} \mathrm{C}\right)$ ocasionou inatividade e redução da ingestão de alimentos em 24 machos castrados.

$\mathrm{Na}$ literatura, foram descritos problemas comportamentais em suínos alojados em ambientes áridos, monótonos, com falta de substratos, levando à frustração que pode refletir em comportamentos anômalos (RADOSTITS et al., 2002; LOPES, 2004). A espécie suína, em particular, também pode modificar o comportamento natural na falta de um ambiente de conforto térmico (RADOSTITS et al., 2002; KIEFER et al., 2009). 
SILVA et al. (2008) realizaram um estudo com 24 matrizes primíparas mantidas em baias individuais e coletivas durante 67 dias. Foram avaliados o comportamento, os índices zootécnicos (período de gestação, duração do parto, número de leitões nascidos vivos, natimortos e mumificados, peso dos leitões no nascimento, peso no desmame e mortalidade) e os parâmetros fisiológicos (frequência respiratória e temperatura retal). Os animais alojados em baias coletivas apresentaram menor incidência de comportamentos estereotipados e agressivos resultantes do estresse térmico. Embora não tenha ocorrido diferença significativa $(\mathrm{P}<0,01)$ pelo teste de Tukey, os índices zootécnicos e os parâmetros fisiológicos dos animais alojados nas baias coletivas apresentaram valores mais adequados às condições de BEA.

A mistura de lotes e a superlotação fazem com que os animais agridam uns aos outros (RADOSTITS et al., 2002). SOUZA (2007) utilizou 24 leitegadas submetidas a três tratamentos: a manutenção da leitegada na baia maternidade, a transferência de uma leitegada para a creche e a mistura de duas leitegadas de nove a 12 semanas alojadas na creche. Verificou-se que a mistura de leitões de diferentes origens foi o fator que mais afetou o BEA, evidenciado pela grande inquietação e pelas interações agonísticas. Essas interações podem causar lesões na pele e aumentar a susceptibilidade do animal às doenças. A mudança de ambiente físico também contribuiu com o estresse durante o desmame e potencializou a incidência de interações agonísticas e a frequência de vocalizações. A manutenção da mesma leitegada na maternidade após o desmame foi o tratamento que demonstrou melhor expressão de comportamentos normais. Os resultados encontrados no trabalho de SOUZA (2007) concordam com a afirmação de RADOSTITS et al. (2002), quando afirma que a miscigenação dos lotes é um fator estressante e altera o comportamento normal.

A importância do ambiente enriquecido (área com turfa, palha, rack e espaço extra) na expressão de comportamentos normais foi estudada por BEATTIE et al. (2000). Nesse estudo, suínos (Landrace x Large White, $\mathrm{n}=320$ ) foram acompanhados desde o nascimento até o abate. Eles foram distribuídos em ambientes áridos (área com piso ripado com o mínimo de espaço recomendado, sem atrativos) e em ambientes enriquecidos. No ambiente enriquecido, o tempo de inatividade e de comportamento agressivo foram reduzidos, enquanto que o tempo gasto para o comportamento exploratório foi aumentado.

\section{Pressão Sonora}

A pressão sonora pode ser facilmente medida com o auxílio de um decibelímetro (BORGES, 2008; TOLON et al., 2010). No Brasil, esse assunto tem sido pouco estudado (CAMPOS, 2009). Os registros do nível de pressão sonora e vocalização destacam-se como metodologia inovadora (não-invasiva) de indicativo comportamental. A vocalização de um grupo de animais tem sido descrita na literatura como nível de pressão sonora, enquanto que a vocalização representa individualmente o animal (BORGES, 2008; NÄÄS et al., 2008). Esse nível pode variar de acordo com as situações ambientais às quais os animais são submetidos, podendo indicar a qualidade de vida deles (SAMPAIO et al., 2007; SOUZA, 2007; BORGES, 2008; NÄÄS et al., 2008; TOLON et al., 2010).

O Departamento do Meio ambiente, Alimentos e Assuntos rurais (DEFRA) do Reino Unido criou o "Código de Recomendação para o Bem-estar na Criação de Suínos". Segundo o código, devem ser evitados valores de pressão sonora acima de $85 \mathrm{~dB}$, assim como a exposição dos animais aos ruídos constantes ou súbidos (DEFRA, 2003). De acordo com TOLON et al. (2010), na presença desse nível de pressão sonora (85dB), o animal pode ficar impossibilitado de desenvolver seu comportamento natural.

MARCHANT et al. (2001) observaram que o suíno realiza uma série de vocalizações com funções distintas. Os grunhidos curtos e longos, assim como os guinchos, podem indicar situações de comportamentos exploratórios e ameaças, bem como fazer contato e excitação demasiada.

BORGES (2008) avaliou os níveis de pressão sonora de leitões na fase de creche e relacionou com o índice de temperatura e umidade do ar. Na faixa de conforto, os níveis de pressão sonora situaram-se entre 54 a 55dB. Na faixa crítica, os níveis de pressão sonora apresentaram tendência de elevação, isto é, 55 a $60 \mathrm{~dB}$. $\mathrm{Na}$ faixa de perigo, houve queda no nível de pressão sonora, ficando entre 56-58dB. Em situações críticas, os leitões tenderam a permanecer deitados, minimizando a perda de calor.

SAMPAIO et al. (2007) também evidenciaram tendências de acréscimos dos níveis de pressão sonora quando os animais são expostos ao desconforto térmico, assim como o ruído de pico durante a alimentação. GUSTAFSSON (1997) afirmou que níveis de pressão sonora acima de $100 \mathrm{~dB}$, encontradas nos horários de arraçoamento, podem indicar a luta por comida, situação desfavorável ao BEA. Além desses fatores estressantes, SOUZA (2007) relatou que a miscigenação dos lotes de leitões, assim como a mudança de ambiente físico dos animais, gera alta frequência de vocalizações. 
Critérios Fisiológicos

Concentração de Cortisol

O Cortisol é um glicocorticóide do eixo Hipotálamo-Pituitária-Adrenocortical (HPA). Ele está envolvido na regulação da absorção de cálcio, na manutenção da pressão sanguínea, na gliconeogenese, na secreção de pepsina e ácidos gástricos e tem função antiinflamatória e imunológica. As variações na sua concentração ocorrem nas reações aos agentes estressores e aos desafios ambientais (DALLACOSTA et al., 2006; KOEPPEN \& STANTON, 2009).

O estresse é um efeito ambiental sobre um indivíduo que sobrecarrega seus sistemas de controle e resulta em consequências adversas (BROOM \& FRASER, 2010). O bem-estar pode variar desde muito bom até muito ruim. Sempre que existe estresse, o bemestar torna-se pobre (BROOM \& MOLENTO, 2004).

A única medida aceitável da presença ou ausência de estresse é o nível sanguíneo de corticosteróides da adrenal (RADOSTITS et al., 2002). VINING et al. (1983) descreveram que o cortisol salivar é a medida mais apropriada para a avaliação clínica da função adrenocortical do cortisol sérico. Um aumento no cortisol sérico se reflete no cortisol salivar em menos de cinco minutos. Além disso, a saliva é um material biológico que pode ser facilmente coletado e obtido de forma não-invasiva, sem provocar estresse no animal.

Em suínos, foram descritos trabalhos sobre a mensuração do cortisol e seus metabólitos no plasma (FAGUNDES et al., 2008), na saliva (DALLA COSTA et al., 2006), nas fezes (PALME et al., 1996) e na urina (HAY \& MORMÈDE, 1998). Nos bovinos, além dos materiais biológicos já descritos, foram utilizados o pêlo (COMIN et al., 2011) e o leite (VERKERK et al., 2008), demonstrando ampla distribuição do cortisol no organismo animal.

DALLA COSTA et al. (2008) avaliaram a concentração do cortisol salivar, por meio da técnica imunoenzimática, em 64 fêmeas suínas adultas, antes, durante e após o transporte. Foi verificado o aumento da concentração do cortisol $\left(0,714 \mu \mathrm{g} \mathrm{dL}^{-1}\right)$ durante o transporte dos animais, com posterior decréscimo $\left(0,510 \mu \mathrm{g} \mathrm{dL}^{-1}\right)$ no período de descanso.

FAGUNDES et al. (2008) avaliaram 36 suínos (Landrace x Large White) machos castrados e fêmeas, entre 74 a 149 dias de idade. Os animais foram distribuídos aleatoriamente em duas condições térmicas de 22,2 a $32,8^{\circ} \mathrm{C}$ e 17,6 a $26,6^{\circ} \mathrm{C}$ e apresentaram, respectivamente, os níveis de cortisol: 7,06 e 4,82mg $\mathrm{dL}^{-1}$, sugerindo que o cortisol pode ser um indicador do estresse térmico.
Temperatura Corporal

Os suínos, quando submetidos à situação de alta temperatura, dispõem de mecanismos metabólicos que agem na manutenção da homeotermia. Assim, a temperatura ambiental influencia na temperatura corporal e superficial do suíno (OMTVEDT et al., 1971; MANNO et al. (2006).

O efeito do ambiente térmico na temperatura retal de 126 fêmeas em gestação foi estudado. Os animais foram distribuídos em câmaras de conforto térmico $\left(23,3^{\circ} \mathrm{C}\right)$ e de estresse por calor $\left(32,2 \mathrm{a} 37,8^{\circ} \mathrm{C}\right)$. A temperatura retal dos animais expostos ao estresse foi significativamente maior $(\mathrm{P}<0,05)$ do que aqueles em conforto (OMTVEDT et al., 1971).

MANNO et al. (2006) avaliaram os parâmetros fisiológicos de suínos (Landrace $\mathrm{x}$ Large White, $n=36$, peso de $29,94 \pm 0,49 \mathrm{~kg}$ ) em situações de conforto $\left(22^{\circ} \mathrm{C}\right)$ e de estresse térmico $\left(32^{\circ} \mathrm{C}\right)$. Foram aferidas as temperaturas do reto, da nuca, da paleta $\mathrm{e}$ do pernil. Os animais sob estresse térmico apresentaram valores das temperaturas superficiais (nuca, paleta e pernil) aproximadamente $9,5 \%$ superiores aos animais submetidos ao conforto térmico.

Frequência Cardíaca

A frequência cardíaca se ajusta para atender à demanda de cada situação emocional. Os altos níveis de frequência cardíaca são produzidos durante atividades físicas excessivas, nas reações de defesa e alarme (CUNNINGHAM, 2003) ou pelo aumento da temperatura corporal (GUYTON \& HALL, 2006).

$O$ estresse provocado pelo transporte também aumenta a frequência cardíaca. DALLACOSTA et al. (2006) avaliaram a frequência cardíaca de 196 fêmeas adultas no período anterior, durante e posterior ao transporte. A frequência cardíaca aumentou $(104,9 \mathrm{bpm})$ no transporte e diminuiu $(91,04 \mathrm{bpm})$ no descanso. Outro estudo, analisando a frequência cardíaca por meio de um monitor, observou que marrãs $(\mathrm{n}=65)$ tiveram a frequência cardíaca aumentada quando em contato com tratador desconhecido (MARCHANT et al., 2001).

Frequência Respiratória

Um dos mecanismos de termorregulação dos suínos pode acontecer pelas vias respiratórias. Em estudo conduzido por TAVARES et al. (2000b), machos castrados $(\mathrm{n}=100)$ foram mantidos em temperaturas de $22^{\circ} \mathrm{C}$ e $32^{\circ} \mathrm{C}$. Eles verificaram que houve aumento da frequência cardíaca nos animais mantidos à temperatura de $33^{\circ} \mathrm{C}$. Em estudo similar, foi observado um aumento na frequência respiratória em temperatura ambiental de $32^{\circ} \mathrm{C}$ (machos castrados, Landrace x Large White, peso 
$29,94 \pm 0,49 \mathrm{~kg}, \mathrm{n}=36$ ). Concluiu-se que a frequência respiratória pode ser aumentada pelo estresse térmico em função da respiração ser um eficiente mecanismo fisiológico que atua na manutenção da termorregulação (MANNO et al., 2006).

Níveis Hematológicos e Bioquímicos Séricos

O perfil hematológico e bioquímico sérico da espécie suína foi estudado em 440 animais, oriundo de 11 propriedades localizadas em diferentes locais do Canadá. Trata-se de uma importante fonte de referência para os valores bioquímicos e hematológicos dessa espécie em diferentes faixas etárias (FRIENDSHIP et al.,1984).

BATISTA et al. (2009) estudaram a influência dos métodos de contenção física e química sobre os parâmetros indicadores de estresse em catetos. Os animais ( $\mathrm{n}=10$, aproximadamente três anos) foram divididos em dois tratamentos: contenção química e a contenção física. A contenção física aumentou significativamente $(\mathrm{P}<0,05)$ os valores do hematócrito, teor de hemoglobina, número de hemácias, leucócitos e os níveis séricos do cortisol, creatina kinase, glicose e lactato desidrogenase. A tranquilização química dos catetos reduziu os parâmetros indicadores de estresse.

\section{Opióides Endógenos}

$\mathrm{O}$ organismo, em resposta às situações adversas, libera os opióides endógenos (betaendorfina, encefalina e dinorfina), que auxiliam no enfrentamento das dificuldades. A mensuração de tais opióides é relevante para avaliar o bem-estar em suínos (BROOM, 1991; ZANELLA et al., 1996).

ZANELLA et al. (1996) relataram que existe correlação negativa entre a quantidade de opióides endógenos e os indicadores comportamentais de baixo BEA. KALBE \& PUPPE (2010) investigaram a expressão do mRNA dos receptores de opióides endógenos cerebrais frente aos estímulos de enriquecimento ambiental cognitivo em suínos. Foi criado um sistema de alimentação que estimulava a cognição e a aprendizagem dos animais, os quais eram recompensados quando efetuavam determinadas tarefas. Por meio da reação em cadeia da polimerase em tempo real (RT-PCR), pôde-se quantificar a expressão dos receptores opióides na amídala e hipotálamo. Os animais alojados em ambientes com enriquecimento cognitivo apresentaram marcada diminuição na expressão dos receptores em relação aos animas alojados em ambientes convencionais.

JANSSENS et al. (1995) avaliaram o mecanismo dos opióides endógenos na resposta do eixo HPA ao estresse agudo em fêmeas suínas. Foram utilizados dois tipos de tratamento: animais sem prétratamento e animais pré-tratados com naloxona (antagonista dos receptores opióides). O estresse agudo foi induzido nos animais por meio do procedimento de contenção nasal por 15 minutos. Nos animais sem pré- tratamento, houve aumento temporário de $\mathrm{ACTH}\left(98 \pm 123 \mathrm{pg} \mathrm{ml}^{-1}\right)$ e cortisol $(54 \pm 3 \mathrm{ng}$ $\mathrm{ml}^{-1}$ ). Naqueles que receberam pré-tratamento com naloxona, ocorreu aumento da resposta de ACTH $\left(244 \pm 36 \mathrm{pg} \mathrm{ml}^{-1}\right)$ e cortisol $\left(65 \pm 5 \mathrm{ng} \mathrm{ml}^{-1}\right)$ em relação aos animais sem pré-tratamento. Conclui-se que o sistema de opiódes endógenos inibe a resposta pituitáriaadrenal em condição de estresse agudo.

\section{Proteínas de Fase Aguda}

As proteínas de fase aguda (PFA) são um grupo de proteínas plasmáticas que contribuem para restaurar a homeostase, modificando suas concentrações em resposta à infecção, inflamação, trauma cirúrgico e estresse (MURATA et al., 2004). Elas são sintetizadas principalmente no fígado, por intermédio das citocinas pró-inflamatórias e sua concentração pode aumentar ou diminuir (PFA negativa), como consequência dos estímulos inflamatórios (BLACK, 2002; PETERSEN et al., 2004; PIÑEIRO et al., 2007). Quando essas proteínas estão aumentadas, indicam comprometimento do BEA (PIÑEIRO et al., 2007). O efeito do estresse sobre a concentração sérica das PFAs é controverso, pois é difícil diferenciá-lo do efeito de um trauma ou infecção subclínica (PETERSEN et al., 2004).

PIÑEIRO et al. (2007) avaliaram a resposta das PFA em suínos durante o transporte. Foram observadas elevações nas concentrações séricas das PFA (Pig-MAP, haptoglobina, amilóide sérico A e proteína C-reativa) imediatamente após a chegada dos animais ao destino, em comparação com amostras séricas deles um mês depois. Elevados índices séricos de PFA são indicativos de estresse durante o transporte.

BURGER et al. (1998) verificaram a concentração plasmática da proteína C-reativa suína (PCRP) em reposta à aplicação de $\mathrm{ACTH}$ em leitões. $\mathrm{O}$ ACTH foi administrado diariamente e monitorado por duas semanas pelo método imunoquímico. Adicionalmente, mensurou-se a concentração plasmática da PCRP. Observou-se que, na ausência de infecções e inflamações, a PCRP pode ser um parâmetro para acompanhar os efeitos do estresse em animais.

Critérios ligados à Sanidade

As interações exatas entre os glicocorticóides e o sistema imunológico não são totalmente compreendidas. A exposição dos animais 
ao estresse afeta a resposta celular e humoral, aumentando a susceptibilidade à doença (BROOM, 1991). Dessa forma, condições de estresse como o reagrupamento de lotes pode ter consequências significativas na função imunológica do animal (MANTEUFFEL, 2002). Em ratos, o estresse agudo provoca mudanças acentuadas, rápidas e reversíveis na distribuição de leucócitos no sangue periférico (DHABBAR et al., 1996). Além disso, verifica-se rápida queda na produção de leucócitos, na capacidade de fagocitose e na secreção de citocinas inflamatórias (TAVARES et al., 2000a).

O estresse diário em fêmeas no terço final da gestação resultou em significativa redução da imunglobulina $\mathrm{G}(\mathrm{IgG})$ nos leitões lactentes no $1^{\circ}$ e e $3^{\circ}$ 을 dias de idade, aumentando significativamente a morbidade e mortalidade (TUCHSCHERER et al., 2002). Outro estudo indica diminuição da resposta imunitária de fêmeas suínas em celas de gestação como sendo consequência do aumento dos níveis de cortisol (ZANELLA, 1995).

Os hormônios esteróides diminuem a imunidade pela redução da função dos granulócitos, monócitos e linfócitos, diminuindo o nível de imunoglobulinas no sangue, que, por sua vez, reduz a imunidade passiva (PIFFER et al., 1998). O período de isolamento social experimental (leitões de 3 a 11 dias) levou ao aumento da concentração basal de cortisol e consequente diminuição da proliferação de linfócitos (KANITZ et al. 2004).

\section{Critérios Ligados à Produção}

Existem evidências de que as respostas fisiológicas ao estresse crônico podem ser responsáveis pela diminuição na produtividade dos suínos (HEMSWORTH et al., 1981). Quando o BEAé comprometido, ocorre retardo ou diminuição do ganho de peso, atraso no início da reprodução, podendo levar os animais à morte (BROOM \& MOLENTO, 2004).

Para que o estresse afete negativamente a reprodução, é necessário considerar os fatores ligados à intensidade do agente estressor, à predisposição genética e o tipo de estresse. Durante o estresse, ocorre a ativação do eixo HPA, que resulta, principalmente, na secreção do hormônio liberador de corticotrofina $(\mathrm{CRH})$ pelo hipotálamo (EINARSSON et al., 2008). O resultado é a inibição do hormônio luteinizante (LH), que tem papel importante na função reprodutiva (TAVARES et al., 2000a). Opióides endógenos também podem afetar a reprodução. BARB et al. (1990) fizeram um estudo in vitro com células hipofisárias de suínos e avaliaram a secreção do LH sob a ação de opiódes endógenos. Foi constatado que os opióides inibem a secreção de LH in vitro.
Além dos fatores reprodutivos, o estresse pode afetar a produção e a qualidade da carne. BEATTIE et al. (2000) concluiram que as taxas de crescimento e a espessura de toucinho foram maiores nos suínos criados em ambientes enriquecidos, comparado com os seus homólogos em ambientes estéreis. Em relação à qualidade de carne, suínos criados em ambientes áridos tiveram maiores perdas de cozimento do que a carne daqueles alojados em ambientes enriquecidos.

\section{CONCLUSÃO}

As avaliações comportamentais, fisiológicas, ligadas à sanidade e à produção, quando associadas, constituem ferramentas eficientes no julgamento do bem-estar dos animais. A ciência do bemestar é recente e pesquisas nessa área são cada vez mais importantes. No entanto, é necessário que haja o desenvolvimento e verificação dos critérios científicos a fim de que venham a ser adotados para avaliação do bem-estar, especialmente, nos sistemas de produção de suínos.

\section{REFERÊNCIAS}

ANDERSEN, I.L. et al. The effects of weight asymmetry and resource distribution on aggression in groups of unacquainted pigs. Applied Animal Behaviour Science, v.68, p.107120, 2000.

BARB, C.R. et al. Opioid modulation of LH secretion by pig pituitary cells in vitro. Journal of reproduction and fertility, v.90, p.213-219, 1990.

BATISTA, J.S. et al. Efeitos da contenção física e química sobre os parâmetros indicadores de estresse em catetos (Tayassu tajacu). Acta Veterinaria Brasilica, v.3, n.2, p.9297, 2009.

BEATTIE, V.E. et al. Influence of environmental enrichment on the behavior, performance and meat quality of domestic pigs. Livestock Production Science, v.65, p.71-79, 2000.

BLACK, P.H. Stress and the inflammatory response: a review of neurogenic inflammation. Brain, behavior and immunity, v.16, n.6, p.622-53, 2002. Disponível em: <http:// www.ncbi.nlm.nih.gov/pubmed/12480495>. Acesso em: 1 mar. 2011. doi: 10.1016/S0889-1591(02)00021-1.

BORGES, G. Utilização da pressão sonora (ruído) como indicativo de bem-estar animal na produção industrial de suínos. 2008. 137f. Dissertação (Mestrado em Agronomia) - Escola Superior de Agricultura Luiz Queiroz, Universidade de São Paulo, SP.

BROOM, D.M. Animal welfare: concepts and measurement. Journal of Animal Science, v.69, p.4167-4175, 1991.

BROOM, D.M.; MOLENTO, C.F.M. Bem-estar animal: conceitos e questões relacionadas - Revisão. Archives of Veterinary Science, v.9, n.2, p.1-11, 2004. 
BROOM, D.M.; FRASER, A.F. Comportamento e bem-estar de animais domésticos. 4.ed. Barueri: Manole, 2010. 438p.

BURGER W. et al. Increase in C-reactive protein in the serum of piglets ( $\mathrm{pCRP}$ ) following ACTH or corticosteroid administration. Journal of Veterinary Medicine. Series B, v.45, n.1, p.1-6, 1998. Disponível em: <http:// www.ncbi.nlm.nih.gov/pubmed/9529990>. Acesso em: 1 mar. 2011. doi: 10.1111/j.1439-0450.1998.tb00759.x.

CAMPOS, J.A. Bem-estar de suínos confinados associado a comportamento, sistema imunológico e desempenho. 2009. 91f. Tese (Doutorado em engenharia agrícola) - Curso de Pós-graduação em Engenharia Agrícola, Universidade Federal de Viçosa, MG.

CANDIANI, D. et al. A combination of behavioral and physiological indicators for assessing pig welfare on the farm. Journal of Applied Animal Welfare Science, v.11, p.113, 2008. Disponível em: <http://www.ncbi.nlm.nih.gov/ pubmed/18444023>. Acesso em: 1 mar. 2011. doi: 10.1080/ 10888700701729080 .

COMIN, A. et al. (in press). Hair cortisol levels in dairy cows from winter housing to summer highland grazing. Livestock Science, 2011. Disponível em: <http://www.journals.elsevierhealth.com/ periodicals/livsci/article/S1871-1413\%2810\%2900610-4/ abstract>. Acesso em: 1 mar. 2011. doi: 10.1016/ j.livsci.2010.12.009.

CUNNINGHAM, J.G. Fisiología veterinaria. 3.ed. Madrid: Elsevier, 2003. 577p.

DALlA COSTA, O.A. et al. Efeito do tempo de jejum dos suínos na granja sobre o bem-estar, medido pelo cortisol na saliva e pela frequência cardíaca, durante o manejo pré-abate. Concórdia: Embrapa Suínos e Aves, 2006. 3p. (Comunicado técnico, 439).

DALLA COSTA, O.A. et al. Tempo de jejum na granja sobre o perfil hormonal e os parâmetros fisiológicos em suínos de abate pesados. Ciência Rural, v.38, n.8, p.2300-2306, 2008. Disponível em: $<\mathrm{http} / / / \mathrm{www}$.scielo.br/scielo.php?script=sci_arttext\&pid=S0103$84782008000800032 \& \operatorname{lng}=$ pt\&nrm=iso $>$. Acesso em: 30 ago. 2010. doi: $10.1590 / \mathrm{S} 0103-84782008000800032$.

DEFRA (Department for Environment, Food \& Rural Affairs). Code of Recommendations for the Welfare of Livestock: Pigs. United Kingdom, 2003. Disponível em: <http:// tinyurl.com/4cwen45>. Online. Acesso em: 21 mar. 2011.

DHABBAR, F.S. et al. Stress-induced changes in blood leukocyte distribution. Role of adrenal steroid hormones. Journal of Immunology, v.157, n.4, p.1638-1644, 1996.

EINARSSON, S. et al. Stress and its influence on reproduction in pigs: a review. Acta Veterinaria Scandinavic, v.50, n.48. p.1-8, 2008.

FAGUNDES, A.C.A. et al. Environmental temperature and serum cortisol levels in growing-finishing pigs. Brazilian Journal of Veterinary Research and Animal Science, v.45, p.136-140, 2008.

FRAJBLAT, M. et al. Ciência em animais de laboratório. Ciência e cultura, v.60, n.2, p.44-46, 2008.
FRASER, D. Animal ethics and animal welfare science: bridging the two cultures. Applied Animal Behaviour Science, v.65. p.171-189, 2000.

FRIENDSHIP, R.M. et al. Hematology and biochemistry reference values for Ontario swine. Canadian Journal of Comparative Medicine, n.48, p.390-393, 1984.

GALHARDO, L.; OLIVEIRA, R. Bem-estar animal: um conceito legítimo para peixes?. Revista de Etologia, v.8, n.1, p.51-61, 2006.

GONYOU, H.W. Why the study of animal behavior is associated with the animal welfare issue. Journal of Animal Science, v.72, n. 8, p.2171-2177, 1994

GRANDIN, T.; JOHNSON, C. O bem-estar dos animais Proposta de uma vida melhor para todos os bichos. São Paulo: Rocco, 2010. 334p.

GUSTAFSSON, B. The health and safety of workers in a confined animal system. Livestock Production Science, v.49, n.2, p.191-202, set. 1997. Disponível em: <http:// www.journals.elsevierhealth.com/periodicals/livest/article/ PIIS0301622697000134/abstract>. Acesso em: 1 mar 2011. doi: 10.1016/S0301-6226(97)00013-4

GUYTON, A.C.; HALL, J.E. Tratado de fisiologia médica. 11.ed. Rio de Janeiro: Elsevier Saunders, 2006. 1263p.

HAY, M.; MORMÈDE, P. Urinary excretion of catecholamines, cortisol and their metabolites in Meishan and Large White sows: validation as a non-invasive and integrative assessment of adrenocortical and symphatoadrenal axis activity. Veterinary Research, v.29, n.2, p.119-28, 1998.

HEMSWORTH. P.H. et al. The influence of handling by humans on the behavior, growth, and corticosteroids in the juvenile female pig. Hormones and Behavior, v.15, n.4, p.396-403, 1981. Disponível em: <http://www.ncbi.nlm.nih.gov/pubmed/ 7327535>. Acesso em: 1 mar. 2011. doi: 10.1016/0018506X(81)90004-0

JANSSENS, C.J. et al. Chronic stress increases the opioidmediated inhibition of the pituitary-adrenocortical response to acute stress in pigs. Endocrinology, v.136, p.1468-1473, 1995. Disponível em: <http://endo.endojournals.org/cgi/content/ abstract/136/4/1468>. Acesso em: 1 mar 2011. doi: 10.1210/ en.136.4.1468

JENSEN, P. The ethology of domestic animals - An introductory text. 2.ed. Wallingford: Cabi, 2009. 264p.

KALBE, C.; PUPPE, B. Long-term cognitive enrichment affects opioid receptor expression in the amygdala of domestic pigs. Genes, Brain and Behavior, v.9, n.1, p.75-83, 2010. Disponível em: <http://onlinelibrary.wiley.com/doi/10.1111/ j.1601-183X.2009.00536.x/full>. Acesso em: 1 mar. 2011. doi:10.1111/j.1601-183X.2009.00536.x.

KANITZ, E. et al. Consequences of repeated early isolation in domestic piglets (Sus scrofa) on their behavioural, neuroendocrine, and immunological responses. Brain, Behavior and immunity, v.18, n.1, p.35-45, 2004. Disponível em: <http://www.ncbi.nlm.nih.gov/pubmed/ 14651945>. Acesso em: 1 mar. 2011. doi: 10.1016/S08891591(03)00085-0. 
KIEFER, C. et al. Resposta de suínos em crescimento mantidos em diferentes temperaturas. Revista Archivos de Zootecnia, v.58, n.221, p.55-64, 2009.

KOEPPEN, B.M.; STANTON, B.A. Berne y Levy: fisiología. 3.ed. Barcelona: Elsevier Mosby, 2009. 834p.

LOPES, E.J.C. Análise do bem-estar e desempenho de suínos em sistema de cama sobreposta. 2004. $111 \mathrm{f}$. Dissertação (Mestrado em agroecossistemas) - Curso de Pósgraduação em agrossistemas, Universidade Federal de Santa Catarina, SC.

MANNO, M.C. et al. Efeitos da temperatura ambiente sobre o desempenho de suínos dos 30 aos 60kg. Revista Brasileira de Zootecnia, v.35, n.2, p.471-477, 2006.

MANTEUFFEL, G. Central nervous regulation of the hypothalamic-pituitary-adrenal axis and its impact on fertility, immunity, metabolism and animal welfare - a review. Archiv für Tierzucht, v.45, n.6, p.575-595, 2002.

MARCHANT, J.N. et al. Vocalisations of the adult female domestic pig during a standard human approach test and their relationships with behavioural and heart rate measures. Applied Animal Behaviour Science, v.72, n.1, p.23-39, 2001.

MOLENTO, C.F.M. Bem-estar e produção animal: Aspectos econômicos - Revisão. Archives of Veterinary Science, v.10, n.1, p.1-11. 2005.

MURATA, H. et al. Current research on acute phase proteins in veterinary diagnosis: an overview. Veterinary Journal, v.168, n.1, p.28-40, 2004. Disponível em: <http:// www.ncbi.nlm.nih.gov/pubmed/15158206>. Acesso em: 1 mar. 2011. doi: 10.1016/S1090-0233(03)00119-9.

NÄÄS, I.A. et al. Uso de redes neurais artificiais na identificação de vocalização de suínos. Engenharia Agrícola, v.28, n.2, p.204-216, 2008 .

OMTVEDT, I.T. et al. Influence of heat stress during early, mid and late pregnancy of gilts. Journal of Animal Science, v.32, p.312-317. 1971.

PALME, R. et al. Excretion of infused 14C-steroid hormones via faeces and urine in domestic livestock. Animal Reproduction Science, v.43, n.1, p.43-63, 1996.

PETERSEN, H.H. et al. Application of acute phase protein measurements in veterinary clinical chemistry. Veterinary Research, v.35, n.2, p.163-187, 2004. Disponível em: <http:/ /www.ncbi.nlm.nih.gov/pubmed/15099494>. Acesso em: 1 mar. 2011. doi: 10.1051/vetres:2004002.

PIFFER, I.A. et al. Efeito de fatores ambientais na ocorrência de doenças. In: SOBESTIANSKY, J. et al. Suinocultura intensiva: produção, manejo e saúde do rebanho. Concórdia: EMBRAPA - CNPSA, 1998. 388p.

PIÑEIRO, M. et al. Characterisation of the pig acute phase protein response to Road transport. Veterinary Journal, v.173, p.669-674, 2007.

POLETTO, R. Bem-estar animal. Suíno.com, Tangará, 5 abr. 2010. Série especial bem-estar animal por Rosangela Poletto. Disponível em: <http://tinyurl.com/4t6z4bk>. Online. Acesso em: 25 jul. 2010.
RADOSTITS, O.M. et al. Clínica veterinária: um tratado de doenças dos bovinos, ovinos, suínos, caprinos e equinos. 9.ed. Rio de Janeiro: Guanagra Koogan, 2002. 1737p.

SAMPAIO, C.A.P. et al. Avaliação do nível de ruído em instalações para suínos. Revista Brasileira de Engenharia Agrícola e Ambiental, v.11, n.4, p.436-440, 2007.

SILVA, I.J.O. et al. Influência do sistema de alojamento no comportamento e bem-estar de matrizes suínas em gestação. Revista Brasileira de Zootecnia, v.37, n.7, p.1319-1329, 2008.

SILVA, I.J.O.; MIRANDA, K.O.S. Impactos do bem-estar na produção de ovos. Thesis, v.6, n.11, p.89-115, 2009.

SNOWDON, C.T. O significado da pesquisa em comportamento animal. Estudos de Psicologia, v.4, n.2, p.365-373, 1999.

SOBESTIANSKY, J.; ZANELLA, J.R.C. Formas anormais de comportamento. In: SOBESTIANSKY, J.; BARCELLOS, D.E.S.N. (Org.). Doenças dos suínos. Goiânia: Cânone Editorial, 2007. p.579-592.

SOUZA, G.P.P. A influência de ambiente físico e social no bem-estar de leitões desmamados. 2007 . 85f. Dissertação (Mestrado em agroecossistemas) - Programa de Pós-graduação em Agroecossistemas, Universidade Federal de Santa Catarina, SC.

TAVARES, M.L. et al. Stress - respostas fisiológicas e fisiopatológicas. Revista Portuguesa de Psicossomática, v.2, n.2, p.51-65, 2000a.

TAVARES; S.L.S. et al. Influência da temperatura ambiente sobre o desempenho e os parâmetros fisiológicos de suínos machos castrados dos 30 aos $60 \mathrm{~kg}$. Revista Brasileira de Zootecnia, v.29, n.1, p.199-205, 2000b.

TOLON, Y.B. et al. Ambiência térmica aérea e acústica para reprodutores suínos. Engenharia Agrícola, v.30, n.1, p.1$13,2010$.

TUCHSCHERER, M. et al. Effects of prenatal stress on cellular and humoral immune responses in neonatal pigs. Veterinary Immunology and Immunopathology, v.86, n.3-4, p.195203, 2002. Disponível em: <http://www.ncbi.nlm.nih.gov/ pubmed/12007885>. Acesso em: 5 abr. 2011. doi: 10.1016/ S0165-2427(02)00035-1.

VERKERK, G.A. et al. Characterization of milk cortisol concentrations as a measure of short-term stress responses in lactating dairy cows. Animal Welfare, v.7, p.77-86, 2008.

VINING, R.F. et al. Salivary cortisol: a better measure of adrenal cortical function than serum cortisol. Annals of Clinical Biochemistry, v.20, p.329-335, 1983.

ZANELLA. A.J. Indicadores fisiológicos e comportamentais do bem-estar animal. A Hora Veterinária, v.14, n.83, p.47$52,1995$.

ZANELLA, A.J. et al. Brain opioid receptors in relation to stereotypies, inactivity, and housing in sows. Physiology \& Behavior, v.49, n.4-5, p.769-775, 1996. Disponível em: <http://www.ncbi.nlm.nih.gov/pubmed/8778865>. Acesso em: 5 abr. 2011. doi: 10.1016/0031-9384(95)02118-3.

Ciência Rural, v.41, n.10, out, 2011. 